\title{
Occurrence and genetic diversity of Cryptosporidium spp. in wild foxes, wolves, jackals, and bears in central Europe
}

\author{
Martin Kváč ${ }^{1,2}$, Eva Myšková ${ }^{2}$, Nikola Holubová ${ }^{1,2}$, Klára Kellnerová2, Marta Kicia ${ }^{3}$, Dušan Rajský ${ }^{4}$, \\ John McEvoy ${ }^{5}$, Yaoyu Feng ${ }^{6,7}$, Vladimír Hanzal ${ }^{8}$ and Bohumil Sak ${ }^{1}$
}

\author{
${ }^{1}$ Institute of Parasitology, Biology Centre of the Czech Academy of Sciences, České Budějovice, Czech Republic; \\ ${ }^{2}$ Faculty of Agriculture, University of South Bohemia in České Budějovice, Czech Republic; \\ ${ }^{3}$ Department of Biology and Medical Parasitology, Wrocław Medical University, Wrocław, Poland; \\ ${ }^{4}$ Faculty of Forestry, Technical University in Zvolen, Zvolen, Slovak Republic; \\ ${ }^{5}$ Veterinary and Microbiological Sciences Department, North Dakota State University, Fargo, USA; \\ ${ }^{6}$ Center for Emerging and Zoonotic Diseases, College of Veterinary Medicine, South China Agricultural University, Guangzhou, China; \\ ${ }^{7}$ Guangdong Laboratory for Lingnan Modern Agriculture, Guangzhou, China; \\ ${ }^{8}$ Faculty of Forestry and Wood Sciences, Czech University of Life Sciences Prague, Czech Republic
}

\begin{abstract}
Parasites of the genus Cryptosporidium Tyzzer, 1910 are one of the most common protistan parasites of vertebrates. Faecal samples from 179 red foxes (Vulpes vulpes [Linnaeus]), 100 grey wolves (Canis lupus Linnaeus), 11 golden jackals (Canis aureus Linnaeus), and 63 brown bears (Ursus arctos Linnaeus) were collected in the Czech Republic, Poland and Slovakia. Samples were examined for the presence of Cryptosporidium spp. using microscopy and PCR/sequence analysis. Phylogenetic analysis based on the small subunit ribosomal RNA (SSU), actin and 60-kDa glycoprotein (gp60) genes using the maximum likelihood method revealed the presence of Cryptosporidium tyzzeri Ren, Zhao, Zhang, Ning, Jian et al., $2012(\mathrm{n}=1)$ and C. andersoni Lindsay, Upton, Owens, Morgan, Mead et Blackburn, $2000(\mathrm{n}=2)$ in red foxes, C. canis Fayer, Trout, Xiao, Morgan, Lai et Dubey, $2001(\mathrm{n}=2)$ and C. ubiquitum Fayer, Santín et Macarisin, $2010(\mathrm{n}=2)$ in grey wolves, and C. galli Pavlásek, 1999 in brown bears $(\mathrm{n}=1)$ and red foxes $(\mathrm{n}=1)$. Subtyping of isolates of C. ubiquitum and C. tyzzeri based on sequence analysis of gp60 showed that they belong to the XIId and IXa families, respectively. The presence of specific DNA of C. tyzzeri, C. andersoni and C. galli, which primarily infect the prey of carnivores, is probably the result of their passage through the gastrointestinal tract of the carnivores. Finding C. ubiquitum XIId in wolves may mean broadening the host spectrum of this subtype, but it remains possible this is the result of infected prey passing through the wolf - in this case deer, which is a common host of this parasite. The dog genotype of C. canis was reported for the first time in wolves.
\end{abstract}

Keywords: PCR, carnivores, genotyping, SSU, gp60, microscopy, Czech Republic, Poland, Slovakia

Cryptosporidium Tyzzer, 1910 is a genus of single-celled parasites that infect the gastrointestinal and respiratory tracts of a diverse range of vertebrate hosts (Fayer 2010, Ryan 2010, Kváč et al. 2014). Infections can result in the diarrhoeal disease, cryptosporidiosis, which can be chronic and even fatal in the absence of a competent immune response; however, no clinical signs are present in many wild animals (Kváč et al. 2014). Early efforts to detect infections with species of Cryptosporidium were based on the description of oocyst morphology, the detection of developing stages in epithelial scratches, or the identification of surface antigen or specific antibodies (Nichols et al. 1991, Nina et al. 1992, Ogunkolade et al. 1993). Nevertheless, these methods lacked the resolution necessary to differentiate morphologically identical, closely related species (Ryan and Xiao 2014).

Due to recent progress in molecular diagnostic techniques, our knowledge of the diversity within Cryptosporidium has markedly increased, with a total of 45 species recognised as well as a similar number of genotypes having been documented to date (Ryan and Xiao 2014, Holubová et al. 2020). Whereas some groups of hosts mainly humans, livestock and pets - are studied intensively, other host groups, including wild carnivores, have so far remained neglected and we know relatively little about the occurrence and diversity of Cryptosporidium spp. in these groups (Kváč et al. 2014, Robertson et al. 2014). 
Table 1. Identification of Cryptosporidium Tyzzer, 1910 in wild wolves, coyotes, foxes, and bears worldwide using microscopy ${ }^{(1)}$, coproantigen test ${ }^{(2)}$, and $\mathrm{PCR}^{(3)}$

\begin{tabular}{|c|c|c|c|c|}
\hline Host (common name) & Country & Cryptosporidium taxa & $\begin{array}{l}\text { No. of positive/ } \\
\text { examined }\end{array}$ & Reference \\
\hline \multirow{5}{*}{$\begin{array}{l}\text { Canis lupus Linnaeus } \\
\text { (grey wolf) }\end{array}$} & Canada & Cryptosporidium sp. ${ }^{(1)}$ & $26 / 1558$ & Bryan et al. (2012) \\
\hline & Canada & Cryptosporidium sp. ${ }^{(1)}$ & $7 / 601$ & Stronen et al. (2011) \\
\hline & Poland & Cryptosporidium sp. ${ }^{(1)}$ & $28 / 51$ & Kloch et al. (2005) \\
\hline & Poland & C. parvum Tyzzer, $1912^{(3)}$ & $5 / 14$ & Paziewska et al. (2007) \\
\hline & Croatia & Cryptosporidium sp. ${ }^{(1,2)}$ & $8 / 400$ & Hermosilla et al. (2017) \\
\hline \multirow{3}{*}{$\begin{array}{l}\text { Canis latrans Say } \\
\text { (coyote) }\end{array}$} & & C. canis coyote genotype $^{(3)}$ & $5 / 22$ & \multirow{3}{*}{ Trout et al. (2006) } \\
\hline & USA & C. muris Tyzzer, $1907^{(3)}$ & $1 / 22$ & \\
\hline & USA & Cryptosporidium sp. ${ }^{(1,3)}$ & $4 / 18$ & \\
\hline \multirow{11}{*}{$\begin{array}{l}\text { Vulpes vulpes (Linnaeus) } \\
\text { (red fox) }\end{array}$} & Slovakia & Cryptosporidium $\mathrm{sp} .{ }^{(2)}$ & $24 / 62$ & Ravaszová et al. (2012) \\
\hline & Ireland & C. parvum $^{(1)}$ & $2 / 464$ & Nagano et al. (2007) \\
\hline & UK & Cryptosporidium sp. ${ }^{(2)}$ & $22 / 184$ & Sturdee et al. (1999) \\
\hline & Norway & Cryptosporidium $\mathrm{sp} .^{(1)}$ & $2 / 269$ & Hamnes et al. (2007) \\
\hline & Iran & Cryptosporidium sp. ${ }^{(1)}$ & $2 / 62$ & Razmjoo et al. (2014) \\
\hline & \multirow{6}{*}{ Spain } & $\begin{array}{l}\text { C. hominis Morgan-Ryan, Fall, Ward, Hijjawi, Su- } \\
\text { laiman, Fayer, Thompson, Olson, Lal et Xiao, } 2002^{(3)}\end{array}$ & $4 / 197$ & \multirow{6}{*}{ Barrera et al. (2020) } \\
\hline & & $\begin{array}{l}\text { C. canis Fayer, Trought, Xiao, Morgan, Lal et Dubey, } \\
2001^{(3)}\end{array}$ & 3/197 & \\
\hline & & C. parvum $^{(3)}$ & $2 / 197$ & \\
\hline & & C. ubiquitum Fayer, Santín et Macarisin, $2010^{(3)}$ & $1 / 197$ & \\
\hline & & $\begin{array}{l}\text { C. suis Ryan, Monis, Enemar, Sulaiman, Read et al., } \\
2004^{(3)}\end{array}$ & $1 / 197$ & \\
\hline & & Cryptosporidium sp. ${ }^{(3)}$ & $1 / 197$ & \\
\hline \multirow{3}{*}{ Vulpes sp. } & \multirow{3}{*}{ USA } & C. canis fox genotype ${ }^{(3)}$ & $4 / 76$ & \multirow{3}{*}{ Zhou et al. (2004) } \\
\hline & & C. canis dog genotype ${ }^{(3)}$ & $1 / 76$ & \\
\hline & & muskrat genotype I ${ }^{(3)}$ & $1 / 76$ & \\
\hline $\begin{array}{l}\text { Vulpes lagopus (Linnaeus) } \\
\text { (arctic fox) }\end{array}$ & Canada & Cryptosporidium sp. ${ }^{(1)}$ & $9 / 95$ & Elmore et al. (2013) \\
\hline $\begin{array}{l}\text { Urocyon cinereoargenteus } \\
\text { (Schreber) (grey fox) }\end{array}$ & USA & Cryptosporidium sp. ${ }^{(1)}$ & $3 / 157$ & Davidson et al. (1992) \\
\hline $\begin{array}{l}\text { Ursus arctos Linnaeus } \\
\text { (brown bear) }\end{array}$ & Slovakia & Cryptosporidium sp. ${ }^{(2)}$ & $35 / 63$ & Ravaszová et al. (2012) \\
\hline $\begin{array}{l}\text { Ursus americanus Pallas } \\
\text { (American black bear) }\end{array}$ & USA & C. canis $^{(3)}$ & $1 / 1$ & Xiao et al. (2000) \\
\hline
\end{tabular}

Several studies reporting the presence of Cryptosporidium spp. in wild wolves, coyotes, foxes, or bears have been published, but most of these works lack genotyping data (for more detail see Table 1). Given the limited scope and number of studies published so far, the present account aimed to describe the occurrence and genetic diversity of Cryptosporidium spp. in wild foxes, wolves, jackals, and bears across the Czech Republic, Poland and Slovakia.

\section{MATERIALS AND METHODS}

In 2015-2018, faecal samples from wild grey wolves (Canis lupus Linnaeus), golden jackals (Canis aureus Linnaeus), red foxes (Vulpes vulpes [Linnaeus]), and brown bears (Ursus arctos Linnaeus) were collected in the Czech Republic, Poland and Slovakia. Faecal samples from foxes were collected from the rectum of animals shot during the hunting season. Wolves, jackals and bears were tracked and their faeces were collected from the ground on the trails or around the lair. The samples were collected in various territories to avoid repeated sampling of the same animals, but it cannot be ruled out that some wolf, jackal or bear was examined repeatedly. Each sample was placed into a separate airtight sterilised container labelled with the animal ID, kept at $4-8^{\circ} \mathrm{C}$ without fixative, and delivered to the laboratory for parasitological and molecular examination. Faecal consistency (loose if it took the form of the container and solid if it maintained its original shape) was noted at the time of sampling.
Presence of oocysts of Cryptosporidium spp. in faecal samples was screened using a light microscope (Olympus IX50, Olympus, Tokyo, Japan) following modified Sheather's sugar flotation method (Eckert et al. 1995) and aniline-carbol-methyl violet staining (Miláček and Vítovec 1985). Total DNA was extracted from $0.2 \mathrm{~g}$ of each faecal sample using the Exgene Stool SV Minikit (GeneAll, Seoul, Korea), which was preceded by homogenisation of the sample by glass beads as previously reported (Sak et al. 2008). Nested PCR protocols were used to amplify a partial region of the small subunit ribosomal RNA (SSU) (Jiang et al. 2005), actin (Sulaiman et al. 2002), and 60-kDa glycoprotein (gp60) (Alves et al. 2003, Li et al. 2014) genes.

Molecular grade water and the DNA of the Cryptosporidium chipmunk genotype were included in each PCR amplification as a negative and positive control, respectively. All samples were analysed in duplicate. Secondary PCR products were separated on an agarose gel, visualised under UV illumination using ethidium bromide staining, purified using the Gen Elute Gel Extraction Kit (Sigma, St. Louis, MO, USA), and directly sequenced by the commercial company SeqMe (Dobříš, Czech Republic).

The nucleotide sequences of each gene obtained in this study were edited using the ChromasPro 2.4.1. (Technelysium, Pty, Ltd., South Brisbane, Australia) and aligned with each other and with reference sequences from GenBank (https://www.ncbi.nlm. nih.gov/pubmed) using the MAFFT version 7 online server with the Q-INS-I algorithm (http://mafft.cbrc.jp/alignment/software/). 
Table 2. Diversity of species of Cryptosporidium Tyzzer, 1910 in faecal samples of red foxes (Vulpes vulpes [Linnaeus]), grey wolves (Canis lupus Linnaeus), golden jackals (Canis aureus Linnaeus), and brown bears (Ursus arctos Linnaeus) detected by microscopy (MIC) and PCR analysis of the small subunit ribosomal RNA (SSU), actin, and $60 \mathrm{kDa}$ glycoprotein (gp60) genes in the Czech Republic (CZE), Poland (POL), and Slovakia (SVK).

\begin{tabular}{|c|c|c|c|c|c|c|}
\hline \multirow{2}{*}{ Host } & \multirow{2}{*}{ Country } & \multirow{2}{*}{$\begin{array}{l}\text { Number of screened/ } \\
\text { MIC/PCR posi- } \\
\text { tive specimens }\end{array}$} & \multirow{2}{*}{ Animal ID } & \multicolumn{3}{|c|}{ Molecular characterisation of Cryptosporidium spp. } \\
\hline & & & & SSU & actin & gp60 \\
\hline \multirow{5}{*}{$\begin{array}{l}\text { Vulpes vulpes (Linnaeus) } \\
\text { (red fox) }\end{array}$} & $\mathrm{CZE}$ & $58 / 0 / 1$ & 13950 & C. tyzzeri & C. tyzzeri & IXaA 8 \\
\hline & POI & $74 / 0 / 2$ & 17238 & C. andersoni & C. andersoni & - \\
\hline & PUL & $14 / 0 / 2$ & 21802 & C. andersoni & C. andersoni & - \\
\hline & SVK & $47 / 0 / 1$ & 13517 & C. galli & C. galli & - \\
\hline & subtotal & $179 / 0 / 4$ & & & & \\
\hline \multirow{5}{*}{$\begin{array}{l}\text { Canis lupus Linnaeus } \\
\text { (grey wolf) }\end{array}$} & $\mathrm{CZE}$ & $17 / 0 / 1$ & 17601 & C. ubiquitum & C. ubiquitum & XIId \\
\hline & & & 29818 & C. canis dog genotype & C. canis dog genotype & - \\
\hline & SVK & $83 / 0 / 3$ & 29819 & C. canis dog genotype & C. canis dog genotype & - \\
\hline & & & 31129 & C. ubiquitum & C. ubiquitum & XIId \\
\hline & subtotal & $100 / 0 / 4$ & & & & \\
\hline \multirow{3}{*}{$\begin{array}{l}\text { Canis aureus (Linnaeus) } \\
\text { (golden jackal) }\end{array}$} & $\mathrm{CZE}$ & $3 / 0 / 0$ & - & - & - & - \\
\hline & SVK & $8 / 0 / 0$ & - & - & - & - \\
\hline & subtotal & $11 / 0 / 0$ & & & & \\
\hline \multirow{2}{*}{$\begin{array}{l}\text { Ursus arctos Linnaeus } \\
\text { (brown bear) }\end{array}$} & POL & $15 / 0 / 0$ & - & - & - & - \\
\hline & $\begin{array}{c}\text { SVK } \\
\text { subtotal }\end{array}$ & $\begin{array}{l}48 / 0 / 1 \\
63 / 0 / 1\end{array}$ & 24444 & C. galli & C. galli & - \\
\hline
\end{tabular}

Phylogenetic trees were inferred by the maximum likelihood (ML) method, with the substitution model that best fit the alignment selected using Bayesian information criterion in the MEGA7 software. Bootstrap support for branching was based on 1,000 replications. Obtained phylograms were edited for style using CorelDrawX7. Sequences have been deposited in GenBank under the accession numbers MT810803-MT810811 and MT822822-MT822833.

\section{RESULTS}

A total of 353 faecal samples of red foxes (179), grey wolves (100), golden jackals (11), and brown bears (63) from the Czech Republic, Poland and Slovakia were examined by microscopy and molecular analysis for the presence of parasites of the genus Cryptosporidium (Table 2). Whereas microscopic examination did not reveal the presence of Cryptosporidium oocysts in any of the samples, Cryptosporidium-specific DNA was detected in five $(2.6 \%)$ samples from red foxes, three $(3.6 \%)$ samples from grey wolves and one $(2.3 \%)$ sample from brown bear (Table 2).

All isolates were successfully sequenced at the SSU and actin genes. ML trees constructed from the alignments of SSU and actin sequences revealed the presence of Cryptosporidium tyzzeri Ren, Zhao, Zhang, Ning, Jian et al., 2012 and C. andersoni Lindsay, Upton, Owens, Morgan, Mead et Blackburn, 2000 in red foxes; C. canis Fayer, Trout, Xiao, Morgan, Lai et Dubey, 2001 and C. ubiquitum Fayer, Santín et Macarisin, 2010 in grey wolves; and C. galli Pavlásek, 1999 in a brown bear and a red fox (Table 2, Figs. 1, 2). At the SSU locus, C. tyzzeri, C. andersoni, C. ubiquitum, and C. galli isolates shared 100\% sequence identity with $C$. tyzzeri (AF112571), C. andersoni (EU245042), C. ubiquitum (EU827424), and C. galli (HM116388), respectively. The isolates of C. canis identified in grey wolves were identical to the C. canis dog gen- otype (AB210854) and differed from C. canis fox, coyote and racoon genotypes (Fig. 1).

At the actin locus, the $C$. tyzzeri isolate was identical to $C$. tyzzeri variant A1 (JQ073406), differing from the variants A2 (JQ073388) and A3 (JQ073414; data not shown). The isolates of C. canis shared $100 \%$ identity with the C. canis dog genotype (EU754837) and differed from the $C$. canis fox and coyote genotypes (Fig. 2). Isolates of C. andersoni, C. ubiquitum and C. galli were identical to the previously reported sequences (Fig. 2).

The gp60 gene was successfully amplified and sequenced only from samples positive for C. ubiquitum and $C$. tyzzeri. Sequences of $C$. ubiquitum were identical to C. ubiquitum subtype family XIId (JX412922) and $C$. tyzzeri sequence clustered together with the $C$. tyzzeri subtype family IXa (Fig. 3). On the basis of the nomenclature for gp60 subtypes (Sulaiman et al. 2005), we detected subtype IXaA8. No loose consistency of faeces was observed in the examined faecal samples.

\section{DISCUSSION}

In the present study, the overall prevalence of Cryptosporidium spp. in wild foxes, wolves and bears was low (0.6-4.0\%), which is similar to previous reports from Canada, Croatia, Iran, Ireland, Norway, Spain, UK, and USA, where the prevalence ranged from $0.4 \%$ to $16 \%$ in these hosts (Sturdee et al. 1999, Hamnes et al. 2007, Nagano et al. 2007, Stronen et al. 2011, Bryan et al. 2012, Razmjoo et al. 2014, Hermosilla et al. 2017, Barrera et al. 2020). In contrast, a few studies from Poland and Slovakia have reported the prevalence of Cryptosporidium spp. to be higher than $35 \%$ in these hosts (Kloch et al. 2005, Paziewska et al. 2007, Ravaszová et al. 2012).

Differences in prevalence among studies are often due to differences in infection rate in individual regions and also different methodological approaches. However, the highest prevalence was observed in studies where the oocysts 


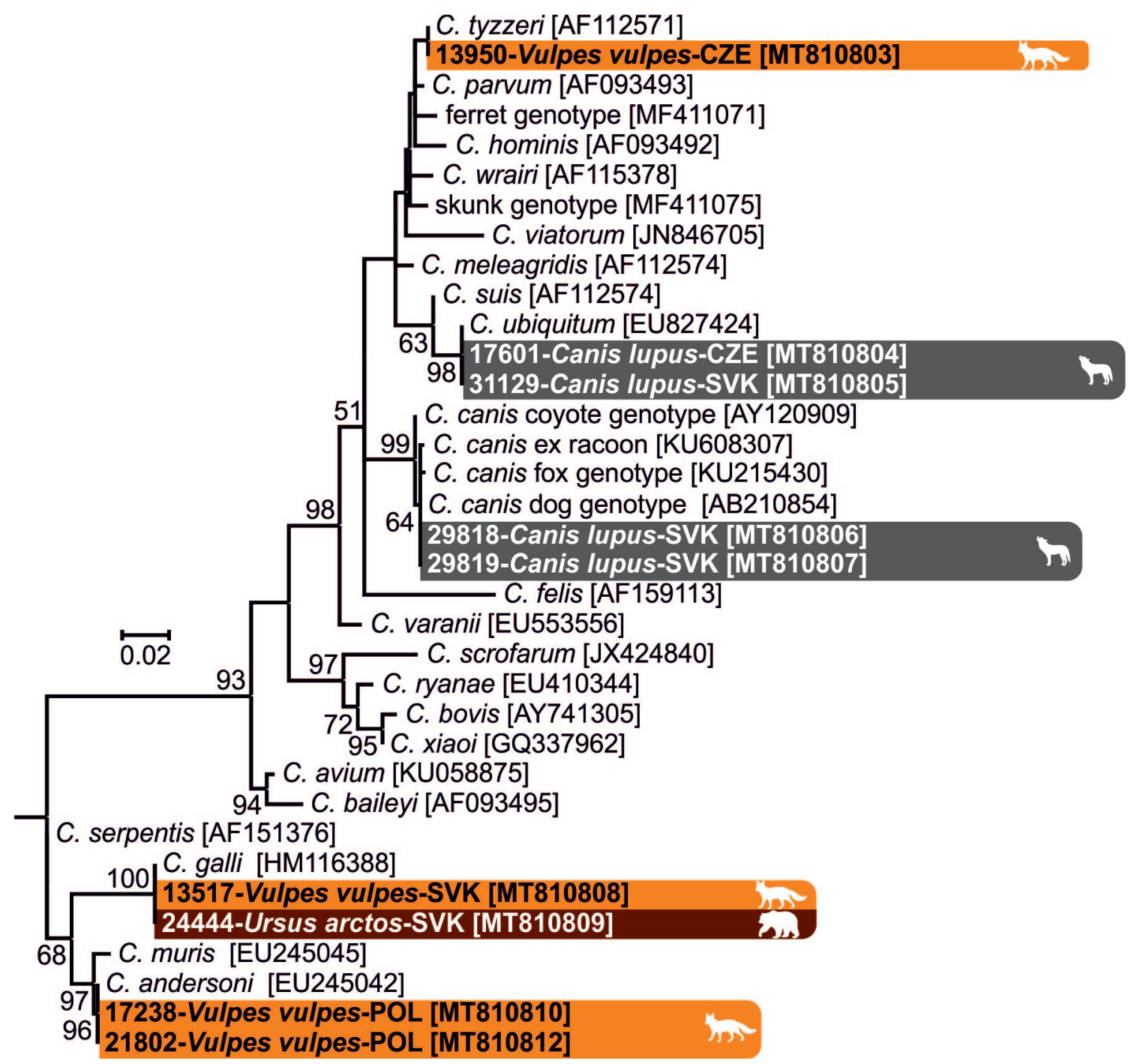

Fig. 1. Molecular phylogenetic tree of Cryptosporidium spp. detected in wild carnivores in this study (highlighted) and other Cryptosporidium spp. available in GenBank using a Maximum Likelihood analysis of partial sequences of the small subunit ribosomal RNA gene. The evolutionary history was interfered based on the Tamura 3-parameter model. A discrete Gamma distribution was used to model evolutionary rate differences among sites. The tree with the highest log likelihood $(-3,000.39)$ is shown. The percentage of trees in which the associated taxa clustered together is shown next to the branches (1,000 replicates). Bootstrap values for the nodes with more than $50 \%$ support are shown. The branch length scale bar indicates the number of substitutions per site. Sequences from this study are identified by an isolate number (e.g., 13517), host species and region (CZE for the Czech Republic, POL for Poland and SVK for Slovakia). The GenBank accession number for each sequence is mentioned in square brackets. The sequence of Plasmodium falciparum [JQ627151] was used as an outgroup.

were detected by microscopy or immunochromatographic methods, which are less sensitive than PCR. The high prevalence in studies from Poland and Slovakia may be a result of local focal infections in the studied populations.

In this study, we did not detect the presence of oocysts of species of Cryptosporidium in any of the examined faecal samples by microscopic methods, although subsequent molecular analyses did reveal their presence. These findings are consistent with results from experimental and field studies performed on a variety of wildlife (Ježková et al. 2016, Čondlová et al. 2018, Kváč et al. 2018). Although cryptosporidiosis is often associated with intestinal disease, similar to previous studies, we did not find any relationship between the occurrence of Cryptosporidium and clinical cryptosporidiosis in wild carnivores (e.g., Sturdee et al. 1999, Zhou et al. 2004, Barrera et al. 2020).

Most of species and genotypes of Cryptosporidium are host-specific (Kváč et al. 2014, Ryan and Xiao 2014). To date, only two studies have genotyped Cryptosporidia in wild bears. Duncan et al. (1999) detected Cryptosporidium parvum Tyzzer, 1912 in tissue sections from the small intestine of a dead black bear cub and Xiao et al. (2000) described the Cryptosporidium bear genotype in a black bear. Canids are considered to be specific hosts of Cryptosporidium canis with distinguishable fox, dog and coyote genotypes (Morgan et al. 2000). Whereas fox and coyote genotypes of $C$. canis have been previously found exclusively in foxes and coyotes, respectively, the C. canis dog genotype has been previously described in dogs, foxes and 


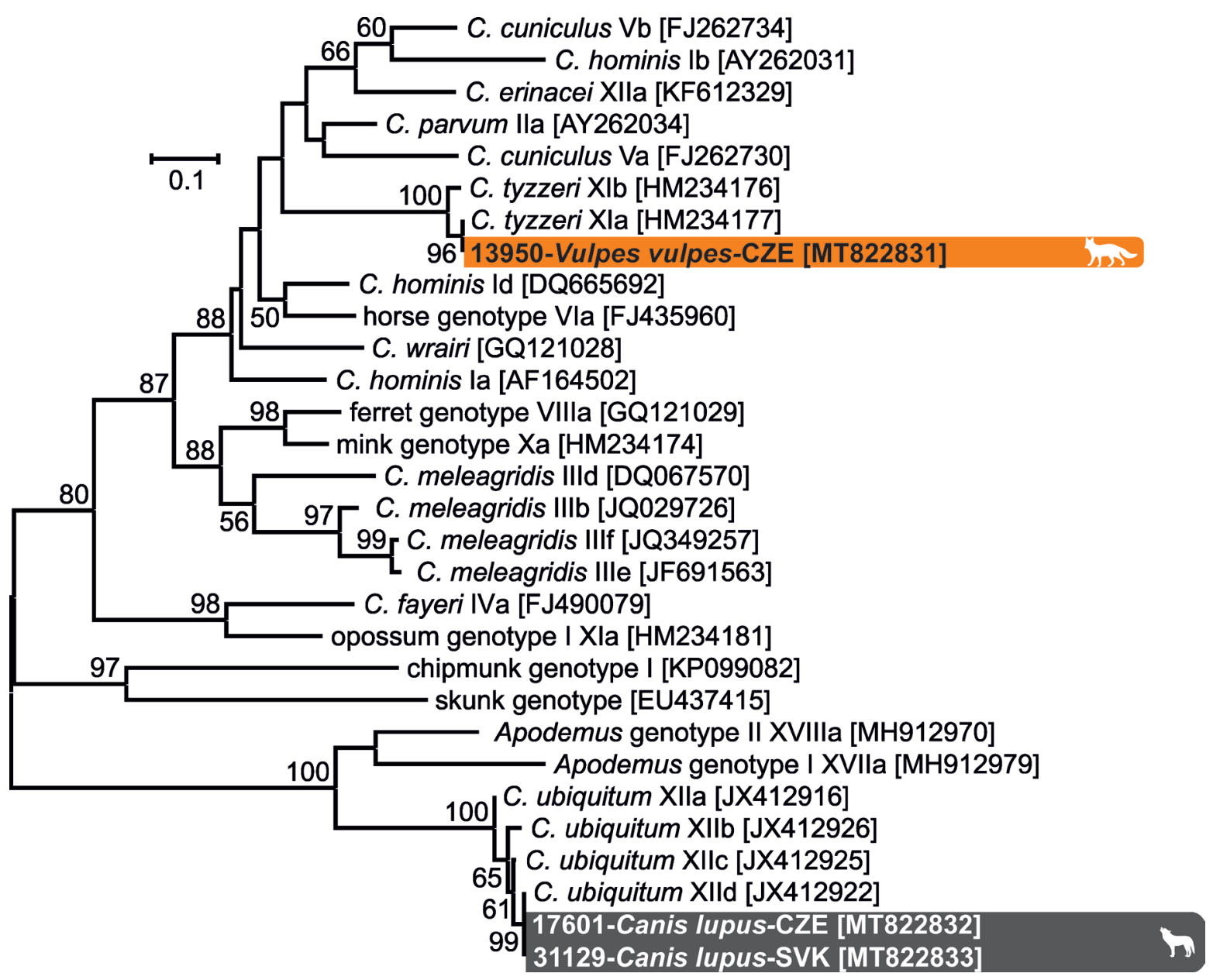

Fig. 2. Molecular phylogenetic tree of Cryptosporidium spp. detected in wild carnivores in this study (highlighted) and other Cryptosporidium available in GenBank using a Maximum Likelihood analysis of partial sequences of the actin gene. The evolutionary history was interfered based on the General Time Reversible model. A discrete Gamma distribution was used to model evolutionary rate differences among sites. The tree with the highest log likelihood $(-5,595.23)$ is shown. The percentage of trees in which the associated taxa clustered together is shown next to the branches (1,000 replicates). Bootstrap values for the nodes with more than $50 \%$ support are shown. The branch length scale bar indicates the number of substitutions per site. Sequences from this study are identified by an isolate number (e.g., 13517), host species and region (CZE for the Czech Republic, POL for Poland, and SVK for Slovakia).The GenBank accession number for each sequence is mentioned in square brackets. The sequence of Eimeria maxima [XM013478337] was used as an outgroup.

minks (Morgan et al. 2000, Zhou et al. 2004, Trout et al. 2006). In the present study, it was found in wolves for the first time. The dog genotype has seemingly a broader host specificity than the other genotypes of $C$. canis, but this may not be true due to the small number of studies.

Most studies of carnivore hosts, including this one, have described the presence of Cryptosporidium spp. that are host-specific for animals other than carnivores. The presence of Cryptosporidium tyzzeri and Cryptosporidium muris Tyzzer, 1907 in the faeces of a red fox and coyotes in this study and that by Trout et al. (2006), respectively, is probably the result of the transfer of these parasites from prey species through the digestive tract. Likewise, the presence of the Cryptosporidium muskrat genotype I (a genotype specific for small rodents) in fox faeces in the study by Zhou et al. (2004) is probably the result of the mechanical passage of oocysts that originated from infected prey. Rodents, which are the typical hosts of these species of Cryptosporidium are common prey of foxes and coyotes (Sturd- ee et al. 1999). Similarly, the presence of specific DNA of Cryptosporidium suis Ryan, Monis, Enemar, Sulaiman, Read et al., 2004 in fox faeces in the study by Barrera et al. (2020) and C. galli in fox and bear faeces in the present study is most likely the result of consuming the carcasses of a wild boar and a bird, as these are the typical hosts of these parasites (C. suis and $C$. galli, respectively) (Němejc et al. 2012, Nakamura and Meireles 2015).

Cryptosporidium andersoni is widely considered a cattle-specific parasite (Lindsay et al. 2000), but has also been found in camels, sheep, goats, various rodents, and non-human primates (Kváč et al. 2016). The presence of $C$. andersoni in the faeces of two foxes shot on a farm with beef cattle can be considered a transfer of the parasite from a contaminated environment. Mechanical passage of non-host-specific species and genotypes of Cryptosporidi$u m$ has been described in the past in a variety of mammals, birds and reptiles (Crawshaw and Mehren 1987, Graczyk et al. 1996, Xiao et al. 2004, Němejc et al. 2013). 


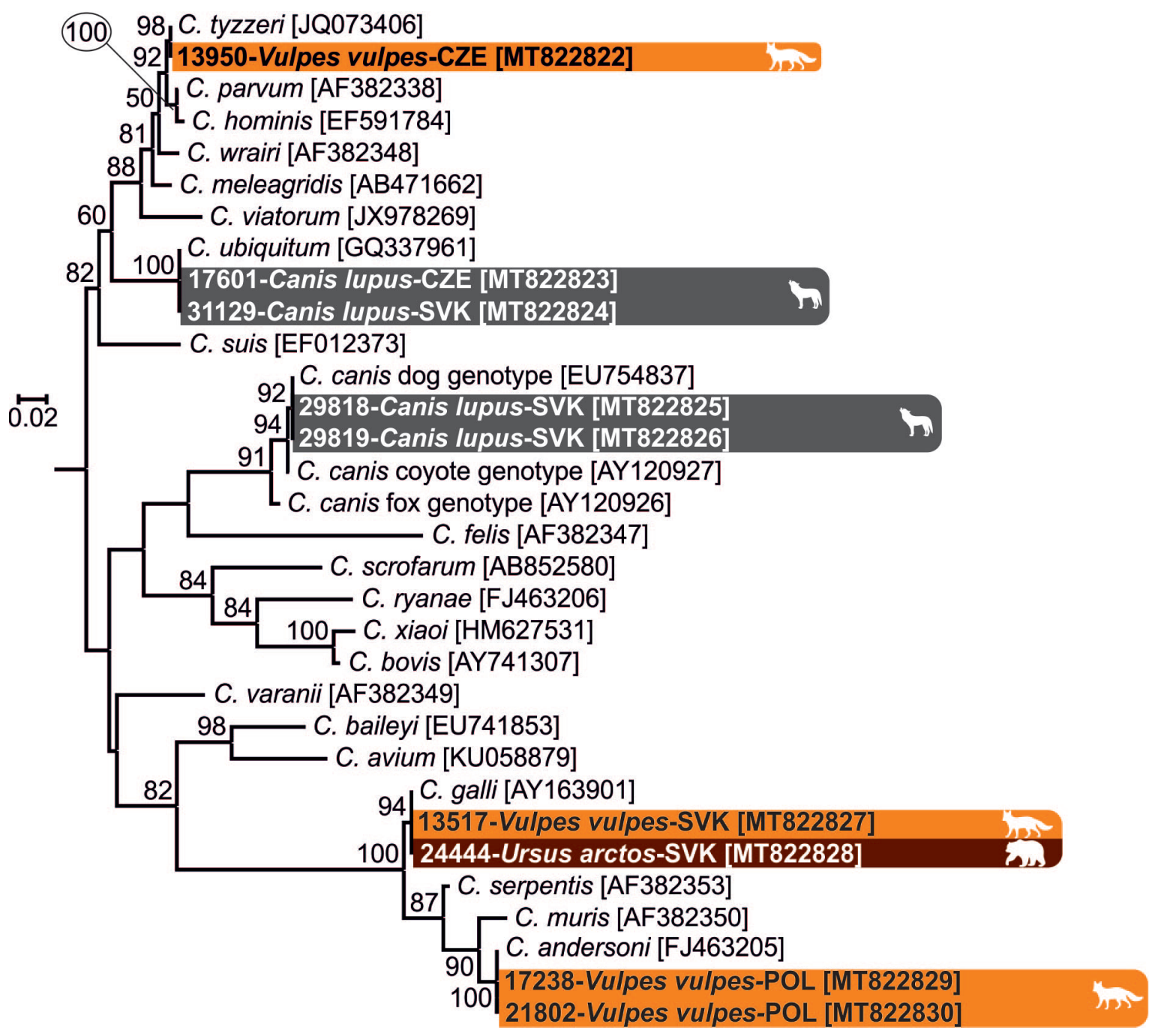

Fig. 3. Molecular phylogenetic tree of Cryptosporidium spp. detected in wild carnivores in this study (highlighted) and other Cryptosporidium available in GenBank using a Maximum Likelihood analysis of partial sequences of the $60 \mathrm{kDa}$ glycoprotein gene. The evolutionary history was interfered based on the General Time Reversible model. A discrete Gamma distribution was used to model evolutionary rate differences among sites. The tree with the highest log likelihood $(-6,836.73)$ is shown. The percentage of trees in which the associated taxa clustered together is shown next to the branches (1,000 replicates). Bootstrap values for the nodes with more than 50\% support are shown. The branch length scale bar indicates the number of substitutions per site. Sequences from this study are identified by an isolate number (e.g., 13517), host species and region (CZE for the Czech Republic, POL for Poland and SVK for Slovakia). The GenBank accession number for each sequence is mentioned in square brackets.

Unlike the above-mentioned Cryptosporidium spp., C. ubiquitum is characterised by broad host specificity. Li et al. (2014) originally suggested that C. ubiquitum gp60 subtype families have different host specificity: subtype XIIa is specific to ruminants and subtype families XIIb-XIId to rodents. However, subtype XIIa has been detected in American minks (Mustela vison Schrebe) and long-tailed chinchillas (Chinchilla lanigera [Molina]) (Kellnerová et al. 2017). Subtype XIId, which was detected in grey wolves in the present study, was identical to those previously found in red deer (Cervus elaphus Linnaeus), raccoon (Procton lotor [Linnaeus]), and crab-eating macaque (Macaca fascicularis [Raffles]) (Li et al. 2014, Kotková et al. 2016, Chen et al. 2019). This suggests that the C. ubiquitum subtype XIId has a broader host range than previously reported; yet, the possibility cannot be entirely ruled out that it was only passing through the wolf after it ate an infected deer.

In conclusion, the results of the present and previous studies show that the use of molecular techniques is very sensitive, enabling even a very small amount of specific DNA to be detected in faecal samples (Lindergard et al. 2003). As experimental studies have shown, the presence of specific DNA without detectable oocysts in the faeces can either indicate active but low intensity infection (Ježková et al. 2016, Kváč et al. 2018), or the passage of oocysts through the gastrointestinal tract (Xiao et al. 2004). However, distinguishing between active infection and the passage of cysts using PCR methods is impossible. Host specificity of the parasite, food preferences of the host and the environment in which the host lives should be used as helpful indicators in deciding between passage and active infection. 
Acknowledgements. We thank the gamekeepers and the staff of the Laboratory of Veterinary and Medical Protistology for their assistance in sample collection during this study. This work was supported by the Ministry of Education, Youth and Sports of the
Czech Republic (project No. LTAUSA17165), by the Grant Agency of the University of South Bohemia (project No. 028/2019/Z), and by the National Natural Science Foundation of China (project No. 31820103014).

\section{REFERENCES}

Alves M., Xiao L.H., Sulaiman I., Lal A.A., Matos O., AnTUNES F. 2003: Subgenotype analysis of Cryptosporidium isolates from humans, cattle, and zoo ruminants in Portugal. J. Clin. Microbiol. 41: 2744-2747.

Barrera J.P., Carmena D., Rodriguez E., Checa R., Lopez A.M., Fidalgo L.E., Galvez R., Marino V., Fuentes I., Miro G., Montoya A. 2020: The red fox (Vulpes vulpes) as a potential natural reservoir of human cryptosporidiosis by Cryptosporidium hominis in Northwest Spain. Transbound. Emerg. Dis.: 67: 2172-2182.

Bryan H.M., Darimont C.T., Hill J.E., Paquet P.C., ThompSON R.C., WaGner B., Smits J.E. 2012: Seasonal and biogeographical patterns of gastrointestinal parasites in large carnivores: wolves in a coastal archipelago. Parasitology 139 781-790.

Chen L., Hu S.H., Jiang W., Zhao J.G., Li N., Guo Y.Q., LiaO C.H., Han Q., Feng Y.Y., Xiao L.H. 2019: Cryptosporidium parvum and Cryptosporidium hominis subtypes in crab-eating macaques. Parasit. Vectors 12: 350.

Crawshaw G.J., Mehren K.G. 1987. Cryptosporidiosis in zoo and wild animals. In R. Ippen and H.D. Schroder (Eds.), Erkrankungen der Zootiere. Verhandlungsbericht des 29 Internationalen Symposiums Uber die Erkrankungen der Zootiere, Cardiff, Akademie-Verlag, Berlin, pp. 353-362.

Čondlová S., HorčičKová M., SAK B., KvĚtoñová D., HlásKová L., Konečný R., Stanko M., McEvoy J., Kváč M. 2018 Cryptosporidium apodemi sp. n. and Cryptosporidium ditrich sp. n. (Apicomplexa: Cryptosporidiidae) in Apodemus spp. Eur. J. Protistol. 63: 1-12.

Davidson W.R., Nettles V.F., Hayes L.E., Howerth E.W., Couvillion C.E. 1992: Diseases diagnosed in gray foxes (Urocyon-Cinereoargenteus) from the Southeastern United-States. J. Wildl. Dis. 28: 28-33.

Duncan R.B., Caudell D., Lindsay D.S., Moll H.D. 1999 Cryptosporidiosis in a black bear in Virginia. J. Wildl. Dis. 35: 381-383.

Eckert J., Braun R., Shirley M.W., Coudert P. 1995: Biotechnology - Guidelines on Techniques in Coccidiosis Research. ECSC-EC-EAEC, Brussels-Luxembourg, 306 pp.

Elmore S.A., Lalonde L.F., Samelius G., Alisauskas R.T., GAJAdhar A.A., JENKIns E.J. 2013: Endoparasites in the feces of arctic foxes in a terrestrial ecosystem in Canada. Int. J. Parasitol. Parasites Wildl. 2: 90-96.

FAYER R. 2010: Taxonomy and species delimitation in Cryptosporidium. Exp. Parasitol. 124: 90-97.

Graczyk T.K., FAyer R., Cranfield M.R. 1996: Cryptosporidium parvum is not transmissible to fish, amphibians, or reptiles. J. Parasitol. 82: 748-751.

Hamnes I.S., Gjerde B.K., Forberg T., Robertson L.J. 2007: Occurrence of Giardia and Cryptosporidium in Norwegian red foxes (Vulpes vulpes). Vet. Parasitol. 143: 347-353.

Hermosilla C., Kleinertz S., Silva L.M., Hirzmann J., HuBer D., Kusak J., Taubert A. 2017: Protozoan and helminth parasite fauna of free-living Croatian wild wolves (Canis lupus) analyzed by scat collection. Vet. Parasitol. 233: 14-19.

Holubová N., Tưmová L., SAK B., Hejzlerová A., KoneČnÝ R., McEvoy J., KvÁč M. 2020: Description of Cryptosporidium ornithophilus sp. n. (Apicomplexa: Cryptosporidiidae) as a new species and diversity in farmed ostriches. Parasit. Vectors 13 340 .
Ježková J., Horčičková M., Hlásková L., Sak B., Květoñová D., Novák J., Hofmannová L., McEvoy J., Kváč M. 2016: Cryptosporidium testudinis sp. n., Cryptosporidium ducismarci Traversa, 2010 and Cryptosporidium tortoise genotype III (Apicomplexa: Cryptosporidiidae) in tortoises. Folia Parasitol. 63: 035 .

Jiang J., Alderisio K.A., Xiao L. 2005: Distribution of Cryptosporidium genotypes in storm event water samples from three watersheds in New York. Appl. Environ. Microbiol. 71: 44464454.

Kellnerová K., Holubová N., Jandová A., Vejčík A., McEvOY J., SAK B., KVÁČ M. 2017: First description of Cryptosporidium ubiquitum XIIa subtype family in farmed fur animals. Eur. J. Protistol. 59: 108-113.

Kloch A., Bednarska M., Bajer A. 2005: Intestinal macro- and microparasites of wolves (Canis lupus L.) from north-eastern Poland recovered by coprological study. Ann. AgriC. Environ. Med. 12: 237-245.

Kotková M., Němejc K., Sak B., Hanzal V., Květoňová D., Hlásková L., Čondlová S., McEvoy J., Kváč M. 2016: Cryptosporidium ubiquitum, C. muris and Cryptosporidium deer genotype in wild cervids and caprines in the Czech RepubliC. Folia Parasitol. 63: 003.

Kváč M., Havrdová N., Hlásková L., Daňková T., Kanděra J., Ježková J., Vítovec J., SaK B., Ortega Y., Xiao L., Modrý D., Chelladurai J.R., Prantlová V., McEvoy J. 2016: Cryptosporidium proliferans n. sp. (Apicomplexa: Cryptosporidiidae): molecular and biological evidence of cryptic species within gastric Cryptosporidium of mammals. PLoS ONE 11: e0147090.

Kváč M., McEvoy J., Stenger B., Clark M. 2014: Cryptosporidiosis in other vertebrates. In: S.M. Cacciò and G. Widmer (Eds.), Cryptosporidium: Parasite and Disease. Springer, Wien, pp. 237-326.

Kváč M., Vlnatá G., Ježková J., HorČičková M., KoneČnÝ R., Hlásková L., McEvoy J., SAK B. 2018: Cryptosporidium occultus sp. n. (Apicomplexa: Cryptosporidiidae) in rats. Eur. J. Protistol. 63: 96-104.

Li N., Xiao L., Alderisio K., Elwin K., Cebelinski E., Chalmers R., Santin M., Fayer R., Kváč M., Ryan U., Sak B., Stanko M., Guo Y., Wang L., Zhang L., Cai J., Roellig D., Feng Y. 2014: Subtyping Cryptosporidium ubiquitum, a zoonotic pathogen emerging in humans. Emerg. Infect. Dis. 20: 217-224.

Lindergard G., Nydam D.V., Wade S.E., Schaaf S.L., MoHAMMED H.O. 2003: The sensitivity of PCR detection of Cryptosporidium oocysts in fecal samples using two DNA extraction methods. Mol. Diagn. 7: 147-153.

Lindsay D.S., Upton S.J., Owens D.S., Morgan U.M., Mead J.R., Blagburn B.L. 2000: Cryptosporidium andersoni n. sp. (Apicomplexa: Cryptosporiidae) from cattle, Bos taurus. J. Euk. Microbiol. 47: 91-95.

MiláČeK P., VítoveC J. 1985: Differential staining of cryptosporidia by aniline-carbol-methyl violet and tartrazine in smears from feces and scrapings of intestinal mucosa. Folia Parasitol. 32: 50 .

Morgan U.M., Xiao L., Monis P., Fall A., Irwin P.J., Fayer R., Denholm K.M., Limor J., Lal A., Thompson R.C. 2000: Cryptosporidium spp. in domestic dogs: the "dog" genotype. Appl. Environ. Microbiol. 66: 2220-2223. 
Nagano Y., Finn M.B., Lowery C.J., Murphy T., Moriarty J., Power E., Toolan D., O'Loughlin A., Watabe M., McCorry K.A., Crothers E., Dooley J.S., Rao J.R., Rooney P.J., Millar B.C., Matsuda M., Elborn J.S., Moore J.E. 2007: Occurrence of Cryptosporidium parvum and bacterial pathogens in faecal material in the red fox (Vulpes vulpes) population. Vet. Res. Commun. 31: 559-564.

Nakamura A.A., Meireles M.V. 2015: Cryptosporidium infections in birds-a review. Rev. Bras. Parasitol. Vet. 24: 253-267.

Němejc K., Sak B., Květoñová D., Hanzal V., Jeníková M., Kváč M. 2012: The first report on Cryptosporidium suis and Cryptosporidium pig genotype II in Eurasian wild boars (Sus scrofa) (Czech Republic). Vet. Parasitol. 184: 122-125.

Němejc K., Sak B., Květoňová D., Kernerová N., Rost M., Cama V.A., Kváč M. 2013: Occurrence of Cryptosporidium suis and Cryptosporidium scrofarum on commercial swine farms in the Czech Republic and its associations with age and husbandry practices. Parasitol. Res. 112: 1143-1154.

Nichols G.L., McLauchlin J., Samuel D. 1991: A technique for typing Cryptosporidium isolates. J. Protozool. 38: 237S-240S.

Nina J.M., McDonald V., Deer R.M., Wright S.E., Dyson D.A., Chiodini P.L., McAdam K.P. 1992: Comparative study of the antigenic composition of oocyst isolates of Cryptosporidium parvum from different hosts. Parasite Immunol. 14: 227-232.

Oates S.C., Miller M.A., Hardin D., Conrad P.A., Melli A., Jessup D.A., Dominik C., Roug A., Tinker M.T., Miller W.A. 2012: Prevalence, environmental loading, and molecular characterization of Cryptosporidium and Giardia isolates from domestic and wild animals along the Central California Coast. Appl. Environ. Microbiol. 78: 8762-8772.

Ogunkolade B.W., Robinson H.A., McDonald V., Webster K., Evans D.A. 1993: Isoenzyme variation within the genus Cryptosporidium. Parasitol. Res. 79: 385-388.

Paziewska A., Bednarska M., Nieweglowski H., KarbowiAK G., BAJer A. 2007: Distribution of Cryptosporidium and Giardia spp. in selected species of protected and game mammals from north-eastern Poland. Ann. AgriC. Environ. Med. 14: 265-270.

Ravaszová P., Halánová M., Goldová M., ValenČáková A., Malčenová B., Hurníková Z., Halan M. 2012: Occurrence of Cryptosporidium spp. in red foxes and brown bear in the Slovak RepubliC. Parasitol. Res. 110: 469-471.
Razmjoo M., Bahrami A., Shamsollahi M. 2014: Seroepidemiological survey of important parasitic infections of wild carnivore. Int. J. Adv. Biol. 2: 783-792.

Robertson L.J., Björkman C., Axén C., Fayer R. 2014: Cryptosporidiosis in Farmed Animals. In: S.M. Cacciò and G. Widmer (Eds.), Cryptosporidium: Parasite and Disease. Springer, Wien, pp. 149-236.

Ryan U. 2010: Cryptosporidium in birds, fish and amphibians. Exp. Parasitol. 124: 113-120.

Ryan U., Xiao L. 2014: Taxonomy and molecular taxonomy. In: S.M. Cacciò and G. Widmer (Eds.), Cryptosporidium: Parasite and Disease. Springer, pp. 3-42.

SaK B., Kváč M., Hanzlíková D., Cama V. 2008: First report of Enterocytozoon bieneusi infection on a pig farm in the Czech RepubliC. Vet. Parasitol. 153: 220-224.

Stronen A.V., Sallows T., Forbes G.J., Wagner B., Paquet P.C. 2011: Diseases and parasites in wolves of the Riding Mountain National Park region, Manitoba, Canada. J. Wildl. Dis. 47: 222-227.

Sturdee A.P., Chalmers R.M., Bull S.A. 1999: Detection of Cryptosporidium oocysts in wild mammals of mainland Britain. Vet. Parasitol. 80: 273-280.

Sulaiman I.M., Hira P.R., Zhou L., Al-Ali F.M., Al-Shelahi F.A., Shweiki H.M., IQbal J., Khalid N., Xiao L. 2005: Unique endemicity of cryptosporidiosis in children in Kuwait. J. Clin. Microbiol. 43: 2805-2809.

Sulaiman I.M., Lal A.A., Xiao L.H. 2002: Molecular phylogeny and evolutionary relationships of Cryptosporidium parasites at the actin locus. J. Parasitol. 88: 388-394.

Trout J.M., Santín M., Fayer R. 2006: Giardia and Cryptosporidium species and genotypes in coyotes (Canis latrans). $\mathrm{J}$. Zoo. Wildlife Med. 37: 141-144.

Xiao L., Limor J.R., Sulaiman I.M., Duncan R.B., Lal A.A. 2000: Molecular characterization of a Cryptosporidium isolate from a black bear. J. Parasitol. 86: 1166-1170.

Xiao L., Ryan U.M., Graczyk T.K., Limor J., Li L., Kombert M., Junge R., Sulaiman I.M., Zhou L., Arrowood M.J., Koudela B., Modrý D., Lal A.A. 2004: Genetic diversity of Cryptosporidium spp. in captive reptiles. Appl. Environ. Microbiol. 70: 891-899.

Zhou L., Fayer R., Trout J.M., Ryan U.M., Schaefer F.W. III., XIaO L. 2004: Genotypes of Cryptosporidium species infecting fur-bearing mammals differ from those of species infecting humans. Appl. Environ. Microbiol. 70: 7574-7577.

Cite this article as: Kváč M., Myšková E., Holubová N., Kellnerová K., Kicia M., Rajský D., McEvoy J., Feng Y., Hanzal V., Sak B. 2021: Occurrence and genetic diversity of Cryptosporidium spp. in wild foxes, wolves, jackals, and bears in central Europe. Folia Parasitol. 68: 002. 